\title{
Characterization of Chirped Pump Four-Wave Mixing in Nonlinear Fibers using only Continuous-Wave-Lasers
}

Lillieholm, Mads; Guan, Pengyu; Møller-kristensen, M. S.; Galili, Michael; Grüner-Nielsen, L.; Oxenløwe, Leif Katsuo

\section{Published in:}

Proceedings of CLEO: Science and Innovations 2017

Link to article, DOI:

10.1364/CLEO_SI.2017.STh4K.4

Publication date:

2017

Document Version

Peer reviewed version

Link back to DTU Orbit

Citation (APA):

Lillieholm, M., Guan, P., Møller-kristensen, M. S., Galili, M., Grüner-Nielsen, L., \& Oxenløwe, L. K. (2017).

Characterization of Chirped Pump Four-Wave Mixing in Nonlinear Fibers using only Continuous-Wave-Lasers.

In Proceedings of CLEO: Science and Innovations 2017 [STh4K.4] Optical Society of America (OSA).

https://doi.org/10.1364/CLEO_SI.2017.STh4K.4

\section{General rights}

Copyright and moral rights for the publications made accessible in the public portal are retained by the authors and/or other copyright owners and it is a condition of accessing publications that users recognise and abide by the legal requirements associated with these rights.

- Users may download and print one copy of any publication from the public portal for the purpose of private study or research.

- You may not further distribute the material or use it for any profit-making activity or commercial gain

- You may freely distribute the URL identifying the publication in the public portal 


\title{
Characterization of Chirped Pump Four-Wave Mixing in Nonlinear Fibers using only Continuous-Wave-Lasers
}

\author{
M. Lillieholm ${ }^{1, *}$, P. Guan ${ }^{1}$, M. S. Møller-Kristensen ${ }^{1}$, M. Galili ${ }^{1}$, L. Grüner-Nielsen ${ }^{2}$, and L. K. Oxenløwe ${ }^{1}$ \\ 1. DTU Fotonik, Dept. of Photonics Engineering, Ørsteds Plads Bldg. 343, DK-2800 Kgs. Lyngby, Denmark \\ 2. OFS, Priorparken 680, DK-2605 Brøndby, Denmark \\ *madsl@fotonik.dtu.dk
}

\begin{abstract}
We propose a novel fiber characterization method that reveals the four-wave mixing bandwidth for chirped pump operation, using two tunable continuous-wave-lasers. The method accurately predicts the bandwidth for optical time lenses with broadband multi-carrier input.

OCIS codes: (060.4370) Nonlinear optics, fibers; (190.4380) Nonlinear optics, four-wave mixing;
\end{abstract}

\section{Introduction and principle}

The time lens [1], based on four-wave mixing (FWM) in highly nonlinear fiber (HNLF) [2], using chirped, flat-top pump pulses to, e.g., perform the optical Fourier transformation [3], is a versatile tool for advanced optical signal processing [4]. However, thus far no systematic characterization procedures for the optimization of such time lenses have been demonstrated. The continuous-wave- (CW) and pulsed-pump FWM bandwidth may differ greatly depending on the fiber properties and pump bandwidth [5], and standard CW-characterizations may be insufficient.

In this paper, we demonstrate a simple technique, which characterizes the bandwidth and conversion uniformity in different HNLFs, for optical Fourier transformations performing WDM to optical time-division multiplexing (WDM-OTDM) conversion. The principle behind WDM-OTDM conversion is illustrated spectrographically in Fig. 1(a), where WDM channels at frequencies $\omega_{s i}$ are converted to chirped idlers at $\omega_{i i}$, by FWM with chirped pump pulses of bandwidth $\Delta \omega_{p}$ at frequency $\omega_{p}$, followed by dispersion to compress and evenly distribute the idler pulses in time. The proposed characterization technique exploits that the local temporal pump spectral content is in the narrowband compared to the total bandwidth. WDM channels typically have low symbol rates, hence the FWM process can be regarded as a series of concurrent, narrowband pump-signal interactions. The process efficiency may then be approximated by the summation of idler efficiency measurements using a CW pump swept over the time lens pump bandwidth, for CW signals centered on each of the WDM channel wavelengths, thus capturing the phase mismatch changes. In Fig. 1(a) the CW signal, pump and corresponding idler positions are indicated by circles. Here it is emphasized that only the spectral content of the pump overlapping with the signal, $\delta \omega_{p}$, should be considered.

\section{Experimental setup, results and discussion}

The HNLF characterization setup for FWM using a chirped pump, is shown in Fig. 1(b). The pump is generated from a tunable CW laser source (TLS), which is phase modulated to suppress stimulated Brillouin scattering. The signal is a TLS, coupling $-6 \mathrm{dBm}$ with the pump into the fiber-under-test (FUT). Finally, the FWM spectrum is

(a) WDM-OTDM/CW time lens characterization
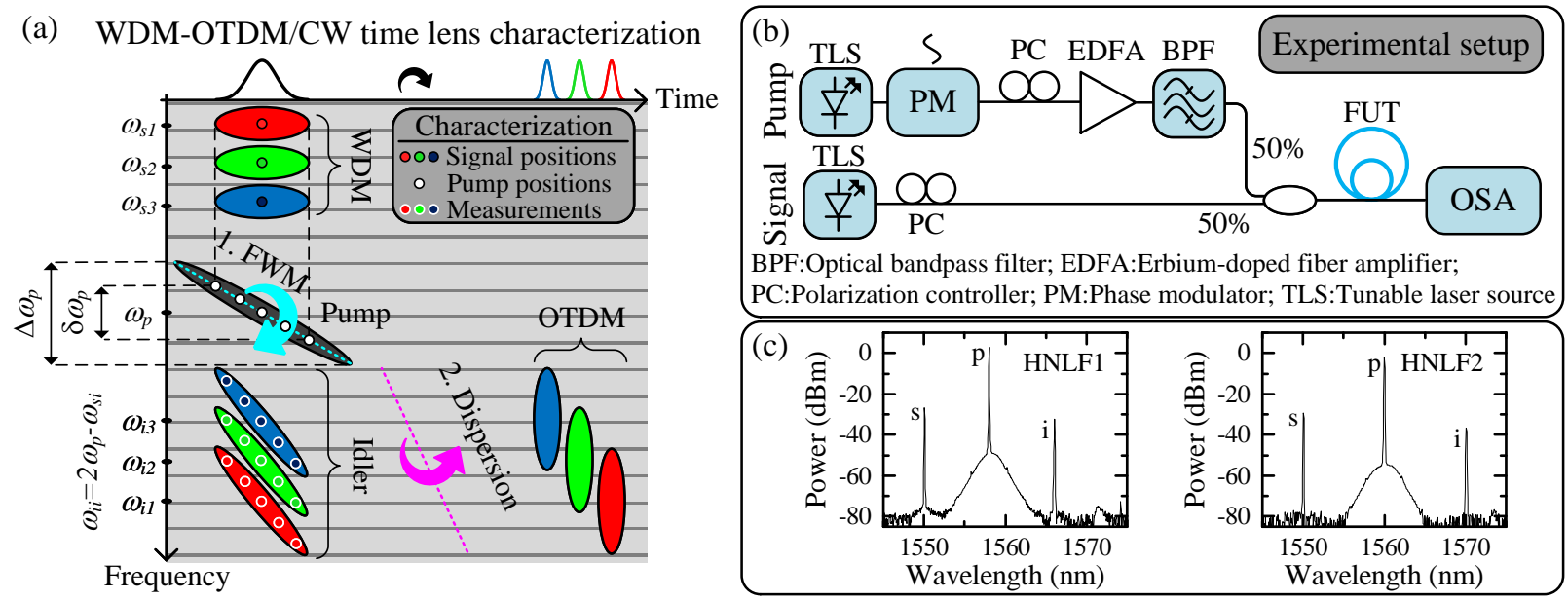

Fig. 1. (a) Principle of WDM-OTDM using a FWM-based time lens and dispersion, with indicated signal, pump and idler frequency positions (circles) to characterize the time lens bandwidth using only CW lasers. (b) Experimental characterization setup. (c) Sample FWM spectra. 

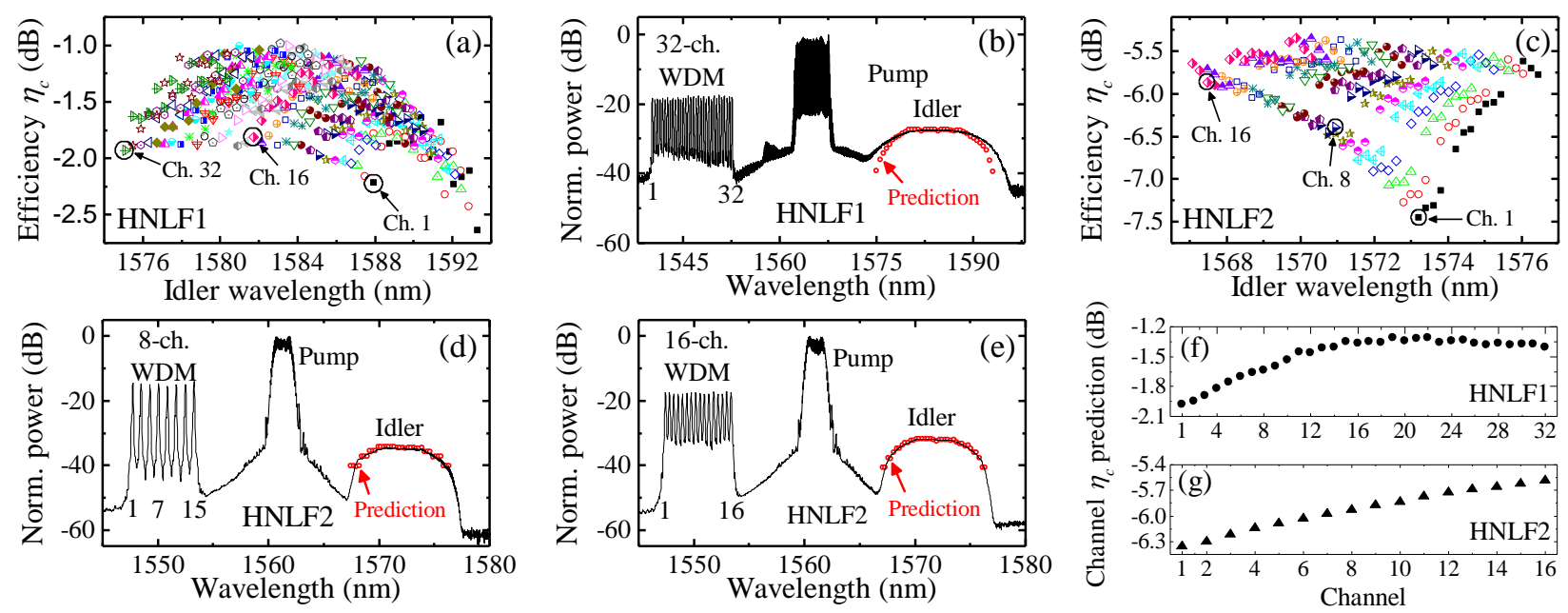

Fig. 2. (a), (c) Conversion efficiency at channel wavelengths with pump swept over $\delta \omega_{p}$. (b), (d), (e) OTDM-WDM time lens spectra with predicted idler spectrum based on measured $\mathrm{CW}$ data superimposed (circles) and (f), (g) estimated relative channel conversion efficiencies.

measured. There are two FUTs: HNLF1, which is a composite dispersion-flattened HNLF with length $L=315 \mathrm{~m}$, zero dispersion wavelength $\lambda_{0}=1560.4 \mathrm{~nm}$, slope $S=0.005 \mathrm{ps} /\left(\mathrm{nm}^{2} \cdot \mathrm{km}\right)$ and nonlinear coefficient $\gamma=$ $10.8(\mathrm{~W} \cdot \mathrm{km})^{-1}$, and HNLF2, which is a standard HNLF with $L=500 \mathrm{~m}, \lambda_{0}=1561 \mathrm{~nm}, S=0.017 \mathrm{ps} /\left(\mathrm{nm}^{2} \cdot \mathrm{km}\right)$ and $\gamma$ $=11.3(\mathrm{~W} \cdot \mathrm{km})^{-1}$. HNLF1 was used for WDM-OTDM conversion of 32 channels with $50 \mathrm{GHz}$ spacing using a pump centered at $1565 \mathrm{~nm}$ with $\sim 4.8 \mathrm{~nm} \mathrm{1-dB}$ bandwidth, and rectangular pulses with $75 \%$ duty cycle (DC) and $25 \mathrm{dBm}$ average power [6]. HNLF2 was used in an experiment for the conversion of 8 and 16 channels with $100 \mathrm{GHz}$ and

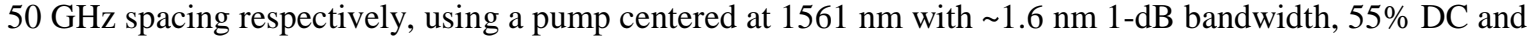
$17.5 \mathrm{dBm}$ average power [7]. Sample CW FWM output spectra for the HNLFs are shown in Fig. 1(c). For HNLF1 the pump was tuned in steps of $0.2 \mathrm{~nm}$ over $\delta \omega_{p}=2.6 \mathrm{~nm}(40 \%$ WDM DC) with $26.3 \mathrm{dBm}$ power ( pulsed peak power) for each of the 32 channel wavelengths. The input conversion efficiencies, $\eta_{c}$, are shown for each channel in Fig. 2(a). The sum of the efficiency curves is superimposed on the corresponding time lens FWM spectrum in Fig. 2(b), showing good agreement, with a 3-dB bandwidth error of 16\%. For HNLF2 the pump was tuned in steps of $0.1 \mathrm{~nm}$ over $\delta \omega_{p}=1.6 \mathrm{~nm}$ with $20.1 \mathrm{dBm}$ power, for each of the 16 channel wavelengths. The resulting efficiency spectra are shown in Fig. 2(c). In Fig. 2(d) the superimposed estimation using data for 8 channels shows extremely good agreement with the time lens FWM idler, and negligible error. Similarly, the results for 16 channels, shown in Fig. 2(e), predicts the shape of the output idler spectrum with high accuracy. The per-channel efficiencies were estimated as the average of the data points for each channel (cf. Fig. 2(a), (c)), shown in Fig. 2(f) and Fig. 2(g). The channel conversion uniformity is estimated to be $0.6-0.7 \mathrm{~dB}$ for the fibers. For the HNLF1 experiment the difference between channels 1 and 32 was $\sim 0.8 \mathrm{~dB}$, indicating that reasonable estimates are obtained, although the absolute values differ by $\sim 2.3 \mathrm{~dB}$. It was found that using short pump step sizes enables the prediction of small features, but coarse step sizes $(\sim 0.5 \mathrm{~nm})$ to reduce the number of measurements, may be sufficient for bandwidth estimation.

\section{Conclusion}

We have proposed a simple method for bandwidth characterization of FWM with chirped pump pulses in HNLFs using only two tunable CW lasers. Accurate bandwidth estimates for the conversion of WDM signals in optical time lenses were obtained, and hence the method shows promise as a tool for the optimization of such systems.

Acknowledgements: Danish Council for Independent Research (DFF), project NANO-SPECs (DFF-4005-00558B).

\section{References}

[1] B. H. Kolner, "Space-time duality and the theory of temporal imaging," IEEE J. Quantum Electron. 30, 1951-1963 (1994).

[2] K. Inoue, "Four-wave mixing in an optical fiber in the zero-dispersion wavelength region," J. Lightwave Technol. 10, 1553-1561 (1992).

[3] H. C. H. Mulvad et al., "Ultra-high-speed optical serial-to-parallel data conversion by time-domain optical Fourier transformation in a silicon nanowire," Opt. Express 19, B825-B835 (2011).

[4] P. Guan et al., "Time lens based optical Fourier transformation for all-optical signal processing of spectrally-efficient data," JLT (2016).

[5] M. Lillieholm et al., "Detailed characterization of CW- and pulsed-pump four-wave mixing in highly nonlinear fibers," Opt. Lett. 41 (2016).

[6] M. Lillieholm et al., "Dispersion-flattened composite highly nonlinear fibre optimised for broadband pulsed four-wave mixing," in European Conference on Optical Communication 2016 (ECOC 2016), paper Tu.2.F.4 (2016).

[7] P. Guan et al., "Conversion of a DWDM signal to a single Nyquist channel based on a complete optical Fourier transformation," in European Conference on Optical Communication 2014 (ECOC 2014), paper We.2.5.5 (2014). 